\title{
INVESTIGATIONS ON THE PERFORMANCE OF INJECTION MOLDED ABS SPUR GEARS
}

\begin{tabular}{|c|c|}
\hline Prashant Kumar Singh*, Siddhartha, Akant Kumar Singh & Sanjay Yadav \\
Department of Mechanical Engineering & Department of Mechanical Engineering \\
National Institute of Technology, Hamirpur & I.T.S Engineering College, Greater Noida \\
Himachal Pradesh, India & Uttar Pradesh, India \\
*nithprashant@gmail.com & \\
\hline
\end{tabular}

\begin{abstract}
Polymer gears are able to replace metallic gears in various engineering applications; but, their mechanical properties are very sensitive to the increasing temperature during their operation. This characteristic limits the wide application of these gears. Different types of polymeric materials and composites have been used for the fabrication of these gears to improve their performance. In this study, Acrylonitrile Butadiene Styrene (ABS) is used in injection molding process to manufacture gears. The molded gears were tested on a power absorbing type gear test rig at the various torques of $0.8,1.2$, and $1.6 \mathrm{Nm}$ with different rotational speed of 600,900 , and $1200 \mathrm{rpm}$. These gears were run against a steel gear and the rise in the surface temperature during mating of these gears was measured along with the specific wear rate of the polymer gear teeth.
\end{abstract}

Keywords-Polymer gear; ABS; injection molding; surface temperatute; specific wear rate

\section{INTRODUCTION}

Gears are mainly used to transmit power and motion in various machines. Gear drives provide better transmission of motion in comparison to the other drives such as belt drives, rope drives, chain drives etc. Metallic gears have been used in various applications for a long time but in modern age, the gears made of polymeric materials are being used increasingly. Polymer gears have various advantages over metallic gears such as: light weight, low noise, ease and speed of manufacture, self-lubrication, ability to dampen moderate shock and impact etc. [1]. The properties of plastic gears are influenced much more than metallic gears by the three main variables: time, temperature, and stress level [2]. There are mainly two types of techniques which are used for the fabrication of these gears: injection molding and machining from a rod [3]. Generally, thermoplastic materials such as Acetal, Nylon 66, Nylon 6, Polycarbonate, Polypropylene etc. are extensively used as polymer gears. Some thermosetting materials such as Polyester and Polyurethane are also used for plastic gearing applications [1]. Plastic gears are most commonly used in printers, photocopy machines and fax machines. The main disadvantage of these gears is their high dependence on temperature and they tend to fail at high temperature under high loading conditions. Polymer gears generally fail either by fatigue or by sudden melting [4]. The different modes of failures which are observed in polymer gears are wear, cracking at root, cracking at pitch circle, and pitting [5].
Acrylonitrile Butadiene Styrene (ABS) is obtained by the modification of styrene which is a combination of the foregoing: a polystyrene terpolymer of acrylonitrile, butadiene, and styrene. ABS is an important thermoplastic for the manufacturing of consumer goods. ABS has excellent toughness and moderately high strength and stiffness. Also, it has good impact strength, heat resistance, and environmental resistance [6]. Due to these properties, ABS can be considered as a suitable material for plastic gearing. When ABS is combined with polycarbonate (PC), the PC/ABS blends have better mechanical properties for the gear applications [7].

\section{WORK METHODOLOGY}

\section{A. Materials and Specifications of the Test Gears}

The materials of the test gears and their specifications are provided in Table 1.

Table 1. Material and specifications of the gear sets

\begin{tabular}{|c|c|c|}
\hline & Driver Gear & Pinion Gear \\
\hline Material & AISI 1040 & $\mathrm{ABS}$ \\
\hline Module (mm) & \multicolumn{2}{|c|}{2} \\
\hline Number of teeth & \multicolumn{2}{|c|}{20} \\
\hline Pressure angle (degree) & \multicolumn{2}{|c|}{20} \\
\hline Face width (mm) & 10 & 8 \\
\hline Diameter of the pitch circle $(\mathrm{mm})$ & \multicolumn{2}{|c|}{40} \\
\hline $\begin{array}{l}\text { Diameter of the addendum circle } \\
(\mathrm{mm})\end{array}$ & \multicolumn{2}{|c|}{44} \\
\hline Contact ratio & \multicolumn{2}{|c|}{1.557} \\
\hline
\end{tabular}

\section{B. Preparation of Specimen}

ABS spur gears were manufactured by injection molding process. Different parameters and their values during the injection molding of ABS gears are summarized in Table 2. 


\section{Asia Pacific Journals}

Table 2. Various parameters and their values during injection molding of plastic gears

\begin{tabular}{|l|l|}
\hline Material & ABS \\
\hline Drying time & $120 \mathrm{~min} .100^{\circ} \mathrm{C}$ \\
\hline Injection pressure & $90 \mathrm{bar}, 2 \mathrm{~s}$. \\
\hline Press temperature & $210^{\circ} \mathrm{C}$ \\
\hline Mold temperature & $40^{\circ} \mathrm{C}$ \\
\hline Waiting time in mold & $25 \mathrm{~s}$. \\
\hline Total cycle time & $40 \mathrm{~s}$. \\
\hline
\end{tabular}

ABS granules were dried for 2 hours at $100^{\circ} \mathrm{C}$ to remove the moisture content present in the material. Gears were injection molded at an injection pressure of 90 bar and a press temperature of $210^{\circ} \mathrm{C}$.

\section{Gear Test}

Test conditions of the gears are given in Table 3. A power absorption type gear test rig was used for the testing of gears. ABS spur gear was attached to a DC motor and driven by an identical AISI 1040 gear attached to an AC motor. Gear test rig is manufactured by DUCOM and can run up to a maximum torque of $4 \mathrm{Nm}$ and rotational speed of $2400 \mathrm{rpm}$. The value of the test torque was obtained by loading the rheostat connected to a generator. Total 9 experiments were performed at different torque $(0.8,1.2$, and $1.6 \mathrm{Nm})$ and speed $(600,900$, and $1200 \mathrm{rpm}$ ) combinations. The temperature at the mating surface of the test gears was continuously measured with the help of a non-contact type temperature sensor placed above the mating surfaces as shown in Fig. 1. The data obtained was stored in a computer based data acquisition system. The wear loss in the plastic gear was obtained by weighing it before and after the test.

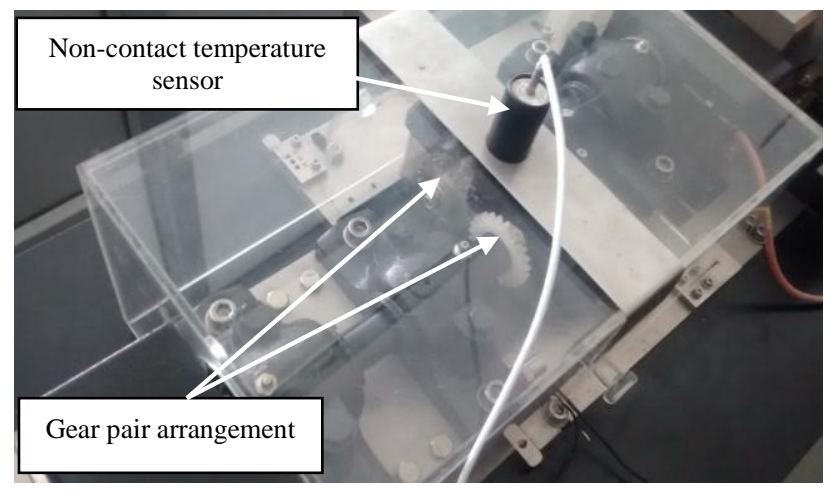

Fig. 1. Gear pair arrangement with non-contact temperature sensor

Table 3. Test conditions

\begin{tabular}{|l|l|}
\hline Applied load (Nm) & $0.6,1.2$ and 1.6 \\
\hline
\end{tabular}

\begin{tabular}{|l|l|}
\hline Rotational speed(rpm) & 600,900 and 1200 \\
\hline Total revolutions & $1.2 \times 10^{5}$ \\
\hline Environment, Temperature & Air, $20-22^{\circ} \mathrm{C}$ \\
\hline Humidity & $30-35 \%$ \\
\hline
\end{tabular}

\section{RESULTS AND DISCUSSION}

\section{A. Specific Wear Rate}

Weight of the ABS spur gears was measured before and after each experiment to obtain the wear loss of the gear. Further, the wear volume was obtained by dividing the wear loss by density of ABS $(1.04 \mathrm{~g} / \mathrm{cc})$. The specific wear rate was calculated as follows $[8,9,10]$ :

$$
\mathrm{W}_{\mathrm{s}}=\frac{\mathrm{W}_{\mathrm{V}}}{2 \mathrm{zmbN}_{\mathrm{T}}}
$$

where $\mathrm{W}_{\mathrm{v}}$ is the wear volume $\left(\mathrm{mm}^{3}\right), \mathrm{z}$ is the number of pinion teeth, $\mathrm{m}$ is the module $(\mathrm{mm}), \mathrm{b}$ is the tooth width $(\mathrm{mm})$, and $\mathrm{N}_{\mathrm{T}}$ is the total number of revolution (rev).

Specific wear rate of ABS gears is shown in Fig. 2 at different load and speed conditions. It is clearly evident from the Fig. 2 that the specific wear rate increases with increase in the load. The wear rate increases more rapidly when the load changes from $1.2 \mathrm{Nm}$ to $1.6 \mathrm{Nm}$ in comparison to that from $0.8 \mathrm{Nm}$ to $1.2 \mathrm{Nm}$.

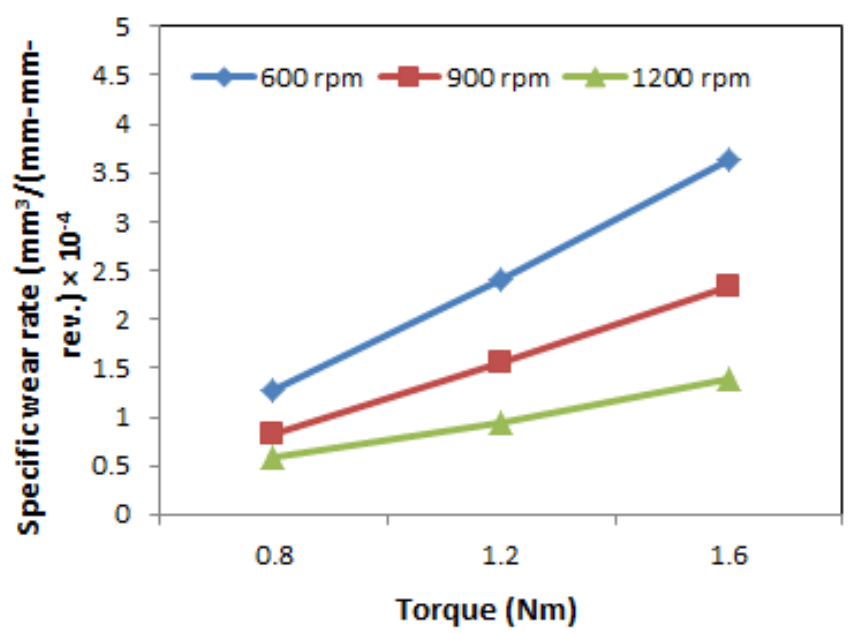

Fig. 2. Variation in specific wear rate of ABS spur gears at different load and speed

It happens due to the fact that the temperature rises quickly at higher loads and the heat accumulated on the gear surface leads to the loosening of material of the gear. Thus, the higher 


\section{Asia Pacific Journals}

load results in the high wear rate of the ABS spur gears. On the other hand, specific wear rate of gears decreases with the increase in the rotational speed of gears. The reduction in the wear rate occurred due to a decrease in the contact period of a single tooth and an increase in the strain rate at higher rotational speeds [11].

\section{B. Tooth Surface Temperature}

Variation in the tooth surface temperature at the mating surface of plastic and steel gear was monitored continuously with the help of a non-contact type temperature sensor. The tests were performed at different loading torque of $0.8,1.2$ and $1.6 \mathrm{Nm}$ for constant rotational speed of 600, 900, and 1200 $\mathrm{rpm}$ respectively. The variation in the tooth surface temperature for each rotational speed is shown in Fig. 3, Fig.4, and Fig. 5, respectively.

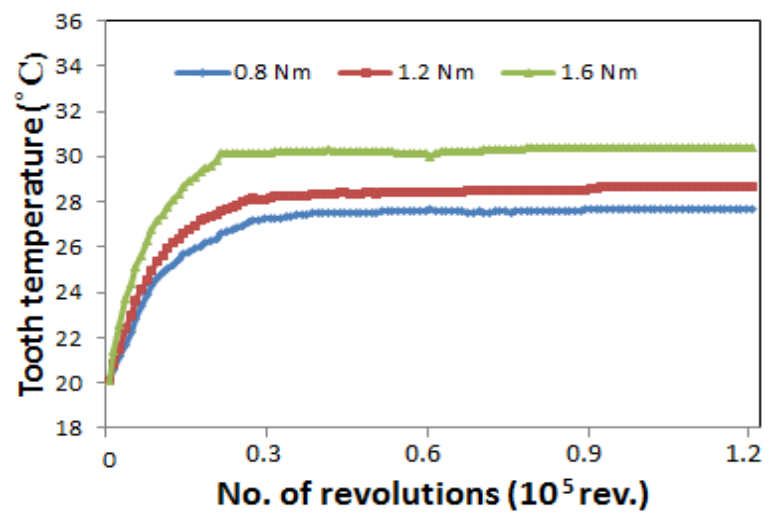

Fig. 3. Variation in the ABS-AISI 1040 tooth temperature at the mating surface for $600 \mathrm{rpm}$

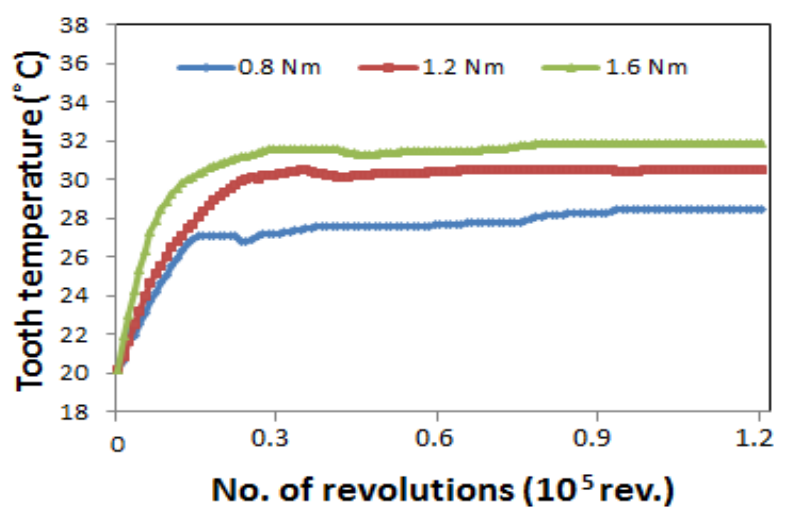

Fig. 4. Variation in the ABS-AISI 1040 tooth temperature at the mating surface for $900 \mathrm{rpm}$

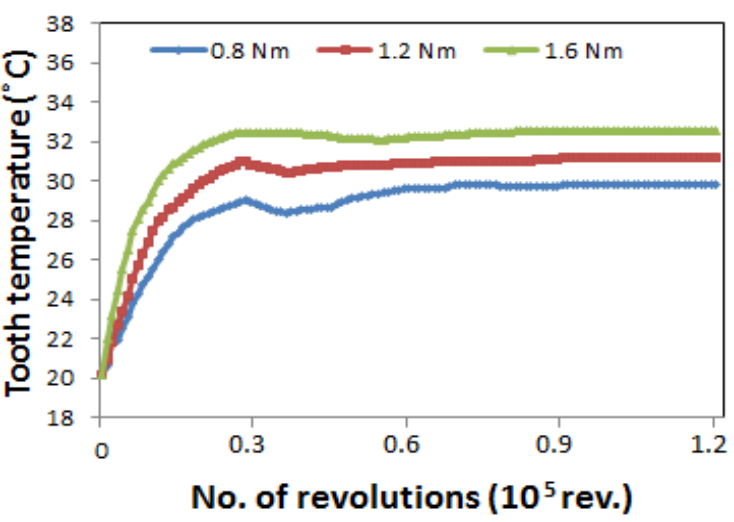

Fig. 5. Variation in the ABS-AISI 1040 tooth temperature at the mating surface for $1200 \mathrm{rpm}$

The accumulated heat at the contact surface mainly occurred by means of the ABS spur gears. The heat that occurred on the surface of the ABS gear was taken by the steel gear and spread out. It is clearly evident from Fig. 3, Fig. 4, and Fig. 5 that the temperature rises with increasing load and becomes constant after completing some number of revolutions. The same pattern is obtained for each rotational speed. It happens due to the fact that after a certain number of revolutions, the thermal equilibrium was achieved.

For rotational speed of $600 \mathrm{rpm}$, an increment of $3.5 \%$ was observed in the surface temperature when load increased from $0.8 \mathrm{Nm}$ to $1.2 \mathrm{Nm}$. The temperature increased by $6 \%$ when load increased from $1.2 \mathrm{Nm}$ to $1.6 \mathrm{Nm}$. In the same manner, a temperature rise of $7 \%$ and $4.5 \%$ occurred for rotational speed of $900 \mathrm{rpm}$. For $1200 \mathrm{rpm}$, the increase in surface temperature was found to be $4.5 \%$ for both load increment conditions (i.e. 0.8-1.2 $\mathrm{Nm}$ and 1.2-1.6 Nm).

From above figures, it is clear that the rise in the surface temperature is affected more significantly by load in comparison to the rotational speed.

\section{CONCLUSIONS}

Injection molded ABS spur gears were tested to understand their wear and thermal behavior using a power absorption type gear test rig. Test gears were run for different load and speed conditions for fixed number of cycles. Following major conclusions were arrived from above investigations:

1. Specific wear rate of ABS spur gear increases with increasing load but decreases with increase in the rotational speed.

2. The rise in the temperature of the mating surface is affected more significantly by load in comparison to the rotational speed.

3. ABS spur gears are suitable for the low load applications because at higher loads, excessive tooth wear takes place. Even these gears may fail under fatigue at high loads. 


\section{Asia Pacific Journals}

\section{References}

[1] C.E. Adams, Plastic gearing: selection and application, New York: Marcel Dekker, 1986, pp. 49-50.

[2] J. Targett and J.E. Nightingale, "Thermoplastic gears," Proc. Instn. Mech. Engrs., vol. 184, pp. 184-194, 1970.

[3] E.S. Narracott, "Plastics in gears," Proc. Instn. Mech. Engrs., vol. 184, pp. 172-176, 1970.

[4] A. Pogacnik and J. Tavcar, "An accelerated multilevel test and design procedure for polymer gears," Mater. Design, vol. 65, pp. 961-973, 2015.

[5] D. Walton and Y.W. Shi, "A comparison of ratings of plastic gears," Proc. Instn. Mech. Engrs., vol. 203, pp. 31-38, 1989.

[6] K.G. Budinski and M.K. Bundinski, Engineering materials: properties and selection, 9th ed., New Jersey: Pearson Education, 2010, pp. 199.

[7] R. Yakut, Load capacity of some thermoplastic gears and experimental investigation of occurring damages, Selcuk University, Natural Science Institution, Konya, 2008.

[8] R. Yakut, H. Duzcukoglu, and M.T. Demirci, "The load capacity of PC/ABS spur gears and investigation of gear damage," Archives of Materials Science and Engineering, vol. 40, pp. 41-46, 2009.

[9] C.H. Kim, "Durability improvement method for polyamide spur gears," Tribol. Int., vol. 39, pp. 1454-1461, 2006.

[10] N. Tasukamoto, H. Maruyama, and H. Mimura, "Effect of reducing friction of polyacetal in gears," Transactions of JSME International Journal Series C, vol. 57, pp. 230-235, 1985.

[11] S. Senthilvelan and R. Gnanamoorthy, "Wear characteristics of injection-moulded unfilled and glass-filled nylon 6 spur gears," J. Eng. Tribol., vol. 218, pp. 495-502, 2004. 